\title{
Radiometry for predicting tallgrass prairie biomass using regression and neural models
}

\author{
K.C. OLSON AND ROBERT C. COCHRAN
}

Authors are research assistant and professor, respectively, Department of Animal Sciences and Industry, Kansas State University, Manhattan, Kan. $66506-1600$

\begin{abstract}
Standing forage biomass (SFB) and the percent of standing biomass composed of forbs (PCTF) were modeled across the growing season. Samples representing stages of plant maturity from early vegetative to dormant were collected from grazed and ungrazed native tallgrass paddocks using a $0.5 \times 0.5 \mathrm{~m}$ quadrat. Total biomass was measured during all years of the study (1992-1995). Grass and forb biomass were measured separately during 1995. Height of canopy closure also was measured during 1995. Before clipping, plots were scanned with a multispectral radiometer. Models were prepared using simple regression, multiple regression (MR), or a commercial neural network (NN) computer program. Potential inputs to MR and NN models of SFB and PCTF included Julian day of harvest (JD), range site, canopy closure height $(\mathrm{CH})$, incident radiation, spectral reflectance values (RFV) at 8 discreet bandwidths, and the normalized difference vegetation index (NDVI). The NDVI alone accounted for little variability $\left(R^{2}=0.13\right)$ in SFB during all years of the study. The optimal MR model for the same data set $(\mathrm{SFB}=$ 3.5[JD] - 43.7[460 nm RFV] + 1099[NDVI] - 992; $\mathbf{R}^{2}=0.62$ ) accounted for a greater amount of the variability in SFB. The capacity to describe variation in SFB for the 1995 data with MR was improved when $C H$ was included as a variable $\left(R^{2}=0.58\right.$ versus 0.78 ). A NN model accounted for the most variation in SFB across the entire study $\left(R^{2}=0.76\right)$. During 1995 , the capability of a NN to account for variation in SFB within the training data was similar whether or not $\mathrm{CH}$ was included as an input $\left(\mathrm{R}^{2}\right.$ = 0.86); however, prediction of SFB from validation data using the same NN was improved by using $C H$ as an input variable. Little variation in PCTF was accounted for by a $\mathbf{M R}$ model $\left(\mathbf{R}^{2}=\right.$ 0.23); however, a considerably larger proportion of the variation in PCTF was accounted for when an NN was used $\left(R^{2}=0.59\right)$. Seasonal changes in SFB and PCTF were described with an acceptable degree of accuracy by forage reflectance characteristics that were adjusted for time of season and canopy complexity. Moreover, when provided with the same potential inputs, NN predicted SFB and PCTF from validation data more accurately than MR models.
\end{abstract}

Key Words: neural networks, remote sensing, multispectral reflectance

\footnotetext{
Contribution No. 97-109-J from the Kansas Agricultural Experiment Station
} Manuscript accepted 14 Mar. 1997.
Measurement of standing forage biomass (SFB) is ubiquitous in the study of prairie ecosystems. Its estimation by hand-clipping techniques is laborious. Moreover, the time and labor required constrain the number of samples that can be collected realistically (Biondini 1992). Ground-based remote sensing devices that measure forage reflectance characteristics have been suggested as alternatives to hand clipping for the estimation of native prairie biomass.

Spectral reflectance in the red and near-infrared (NIR) portions of the spectrum is related directly to above-ground forage biomass (Pearson et al. 1976). Richardson and Everitt (1992) noted that remote sensing procedures often transform red and NIR spectral waveband measures into vegetation indices. Indices such as the NIR:red ratio and the normalized difference vegetation index (NDVI) reduce measurement variability due to soil type, sunlight intensity, and angle of sunlight incidence. Reflectance in the green and blue portions of the spectrum has been used to predict agronomic traits of forages such as leaf area index and vigor (Hinzman et al. 1986). In some cases, these measures have been incorporated into a 'greenness' index (Miller et al. 1984); however, few models of aboveground biomass have been proposed that integrate multiple, biophysically meaningful wavebands.

Development of accurate, generalizable models to predict forage biomass from reflectance data is challenging. Ideally, validation data should encompass a wide variety of biomass levels, forage maturities, and growing conditions and should involve several growing seasons. Simple models composed of few variables are often inadequate to describe such variation (Jackson et al. 1983, Anderson and Hanson 1992). Complex models have been proposed to describe forage biomass across multiple stages of forage maturity (Jensen et al. 1990, Mitchell et al. 1990) but robust models can be difficult to derive from highly variable time series data. This is particularly true when the relationship between the dependent variable and the independent variables deviates from linearity or the underlying reasons for the relationship are not understood completely (Kohzadi et al. 1995).

Recent availability of commercial neural network (NN) software has provided new opportunity for the development of robust predictive models. Neural networks are highly parallel, dynamic learning systems that simulate the human inductive reasoning process (Stanley and Bak 1988). They learn by example, making predictions based on experience. As a NN's experience increases, its predictive power also increases. Conventional modeling tools rely on a rigid set of programmed rules to make predictions. As such, they lack the ability to recognize subtle relationships among data and have low tolerance for error. Neural networks have a 
high tolerance for error because of their inductive nature (Kohzadi et al. 1995). Moreover, they have been shown to outperform statistical methods when predicting nonlinear responses (Thai and Shewfelt 1991, Bochereau et al. 1992).

Our primary objective was to develop robust predictive models of seasonal change in tallgrass prairie standing forage biomass (SFB) and the percent of standing biomass attributable to forbs (PCTF) from radiometric reflectance data. Secondarily, we wished to compare the efficacy of neural networks (NN) with that of regression procedures for modeling SFB and PCTF from similar input variables.

\section{Materials and Methods}

Study Area. Research was conducted at the Kansas State University Range Research Unit located near Manhattan, Kans. The study area included 4 paddocks. Three of the paddocks (average size $=34 \mathrm{ha}$ ) were grazed by domestic cattle as part of a long-term grazing systems study (Olson et al. 1995). Livestock were excluded from the remaining paddock ( $18 \mathrm{ha}$ ).

Vegetation and soils on the site were described by Anderson and Fly (1955). Major grass species were big bluestem (Andropogon gerardii Vitman), indiangrass (Sorghastrum nutans Nash), switchgrass (Panicum virgatum L.), and little bluestem (Schizachyrium scoparium (Michx.) Nash). Principal overstory forbs included leadplant (Amorpha canescens (Nutt.) Pursh), Baldwin's ironweed (Vernonia baldwini Torr.), slimflower scurfpea (Psoralea tenuiflora Pursh), and blue wildindigo (Baptisia minor Lehm.). Woody plant species such as smooth sumac (Rhus glabra L.) and buckbrush (Symphoricarpus orbiculatus Moench) also occurred on the site but were encountered infrequently. Site soils were transitional from Ustolls to Udolls (Owensby et al. 1988). Loamy upland, clay upland, and limestone breaks were the primary range sites (Anderson and Fly 1955).

Data Collection. Standing forage biomass was measured from 1992 to 1995 in each of the major range site types within each paddock. Standing forage biomass was measured only once in 1992 and 1993 but was measured 5 and 7 times during 1994 and 1995, respectively (Table 1). During 1994 and 1995, dominant warm-season grasses were phenologically immature at the outset of measurements and dormant at the time when the final samples were collected. Approximately equal numbers of samples were collected from each range site.

Measurements were conducted along temporary transects ( 75 $m$ ) identified on each collection day. Individual plots were spaced at regular intervals along transects. Plots ( $1 \mathrm{~m}$ in diameter) were scanned with an aerial-view multispectral radiometer from $2 \mathrm{~m}$ above ground between 1100 and 1600 hours. Other pertinent information collected at the time of the scan included: Julian date, incident radiation $\left(\mathrm{W} \mathrm{m}^{-2}\right)$, and range site type. The radiometer used in this study (Model 87, Cropscan ${ }^{\circledR}$, Inc. ${ }^{1,2}$ ) was fitted with filters for measuring spectral reflectance at 8 specific wavebands (32 nm; approximate center wavelength $=460,510,560,610$, $660,710,760$, and $810 \mathrm{~nm}$ ). A data acquisition device (DLC Model 92, Cropscan ${ }^{\circledR}$, Inc. ${ }^{1}$ ) equipped with sunangle cosine correction capability was used to record reflectance data.

Radiometer calibration was conducted daily with an opal glass diffuser using the two-point minimum/maximum irradiation method (Cropscan 1994). In addition, 1 of the radiometer's filters
Table 1. Summary of Collection Dates

\begin{tabular}{lcccccc}
\hline \hline $\begin{array}{l}\text { Julian } \\
\text { Date }\end{array}$ & Year & $\begin{array}{c}\text { Plots } \\
\text { Ploean }\end{array}$ & $\begin{array}{c}\text { Minimum Maximum } \\
\text { Biomass }\end{array}$ & $\begin{array}{c}\text { Standard } \\
\text { Biomass }\end{array}$ & Biomass & Deviation \\
\hline 150 & 94 & 30 & 178.6 & 124.9 & 244.6 & 29.8 \\
166 & 95 & 30 & 200.6 & 53.3 & 443.4 & 109.3 \\
173 & 95 & 30 & 279.7 & 89.1 & 491.3 & 139.4 \\
175 & 94 & 30 & 353.6 & 200.5 & 516.5 & 83.4 \\
180 & 95 & 27 & 279.6 & 84.7 & 526.0 & 134.7 \\
211 & 92 & 60 & 194.1 & 53.7 & 442.7 & 102.7 \\
223 & 95 & 30 & 356.4 & 154.1 & 648.1 & 121.3 \\
229 & 95 & 30 & 408.7 & 133.4 & 691.6 & 199.0 \\
236 & 95 & 30 & 437.1 & 165.4 & 651.2 & 136.2 \\
241 & 94 & 30 & 368.7 & 254.2 & 580.3 & 84.0 \\
252 & 94 & 30 & 491.6 & 343.8 & 696.8 & 79.1 \\
259 & 94 & 30 & 455.3 & 175.1 & 767.6 & 116.6 \\
271 & 95 & 30 & 306.6 & 83.2 & 554.2 & 155.7 \\
294 & 93 & 134 & 228.5 & 22.7 & 762.0 & 140.9 \\
\hline
\end{tabular}

was calibrated to serve as an internal pyranometer using a LI-COR model LI-200SA pyranometer (Omnidata International ${ }^{\mathbb{R}}$, Inc. ${ }^{3}$ ).

Actual standing forage biomass (SFB) was measured immediately after the radiometer scan. Vegetation was clipped at ground level within a frame $(0.5 \times 0.5 \mathrm{~m})$ placed in the center of the plot. Clipped forage was placed into paper bags and dried for 96 hours at $50^{\circ} \mathrm{C}$ to determine dry SFB. During the 1995 growing season, clipped forage was separated into grass and forb components. Grasses and forbs were dried and weighed separately to determine their relative contributions to SFB.

A Robel pole measurement was made at each plot $(n=207)$ during 1995 concurrent with the radiometer scan (Robel et al. 1970). The height of canopy closure (m) was estimated from 4 equidistant points around the Robel pole from a distance of $4 \mathrm{~m}$ and at a height of $1 \mathrm{~m}$. The 4 estimates were averaged for each plot.

Modeling Procedures. For each individual plot $(n=551)$ the following data were available: Julian day of harvest (JD), range site type, incident radiation, reflectance values (RFV) for each waveband, and the normalized difference vegetation index (NDVI; $(810 \mathrm{~nm}-610 \mathrm{~nm}) /(810 \mathrm{~nm}+610 \mathrm{~nm})$; Biondini 1992). In addition, canopy closure height $(\mathrm{CH})$ and the percentage of biomass attributable to forbs (PCTF) were collected from plots measured in $1995(n=207)$.

Approximately $10 \%$ of the plots (i.e. validation data) from each harvest date/range site subgroup were removed randomly from the data set for use in evaluating predictive accuracy of models. The remaining data points (i.e., training data) were used to construct neural network (NN) and regression models. Additionally, plots measured during 1995 were modeled as a discreet subgroup of the main data set.

Multiple regression (MR) models of SFB and PCTF were prepared from training data using the stepwise regression procedure of SAS (SAS Institute 1985). The level of significance specified for entry and retention of variables in the model was $P<0.10$. Linear models were constructed using 1 to 12 variables for the

\footnotetext{
Cropscan, Inc., 125 26th St. NW, Rochester, Minn. 55901.

2 Trade and company names are included for the benefit of the reader and imply no endorsement by Kansas State University.

${ }^{3}$ Omnidata International, Inc., P.O. Box 448, Logan, Ut. 84321
} 
main data set and 1 to 13 variables for the 1995 subset. The MR model was considered to be optimal when: 1) further increases in the coefficient of determination were minor (e.g., 1 or 2 hundredths of a unit) and 2) significant decreases in the error mean square were no longer apparent. Each MR model was validated by using it to predict SFB or PCTF from the validation data set. Measured values from the validation data were compared with predicted values to evaluate accuracy.

Neural networks were developed with a commercially available software package (Braincel ${ }^{\circledR}$ Ver. 2.5, Promised Land Technologies, Inc ${ }^{4}$.) using the same training data and input variables as in the MR modeling procedure. All NN's were developed using a back-percolation learning algorithm, a variant of back-propagation, with a single layer of hidden nodes (Jurik 1993). Zhuang and Engel (1990a) provide an excellent overview of the mechanics of back-propagation algorithms. The Braincel ${ }^{\circledR}$ best-net-search procedure was used to determine optimal node configuration and weight randomization. The Braincel ${ }^{\circledR}$ leaveout procedure was performed on each fully trained NN to determine the relative importance of inputs in predicting the variable of interest. Prediction error on training and validation data and the number of nodes in the hidden layer were recorded. Predictive accuracy of NN models was assessed in the same manner used for MR models.

The NDVI has been used frequently to predict SFB and leaf area index in graminoid-dominated plant communities (Anderson and Hanson 1992, Aase et al. 1987). Therefore, a simple linear regression of NDVI versus biomass was prepared to compare the results of the current trial with those of previous studies. Validation was conducted in the same manner described for the $\mathrm{NN}$ and MR models.

\section{Results and Discussion}

Simple Regression Models. The NDVI alone accounted for little variation in standing forage biomass (SFB) across the growing season (Fig. 1a). Although the slope and intercept of this model were highly significant, the standard error of the estimate was extremely large. Subsequent prediction of SFB from data withheld from model construction ( i.e. validation data; Fig. 1b) was poor. Similarities between the regression line and the isopleth ( $x$ $=y$ ) indicated little bias was associated with predicting SFB from NDVI in this study; however, the relationship between NDVI and SFB remained very weak and was characterized by predicted values that fell in a much narrower range than actual SFB values.

Aase et al. (1987) reported a strong season-long relationship between NDVI and dry biomass on native pastures in the Northern Great Plains but their data were generated from permanent plots that were measured repeatedly during the growing season. In contrast, Anderson and Hanson (1992) demonstrated a poor association between NDVI and biomass of semiarid grasslands when randomly selected plots were sampled. They suggested that the large amount of standing dead plant material and litter in experimental plots contributed to the weak relationship. Litter and standing dead material were minimized in our study by annual burning; however, the SFB was characterized by significant changes over time in the amount of green versus senescent mater-

\footnotetext{
4Promised Land Technologies, Inc. 900 Chaptel St., Suite 300, New Haven, Conn. 06510 .
}
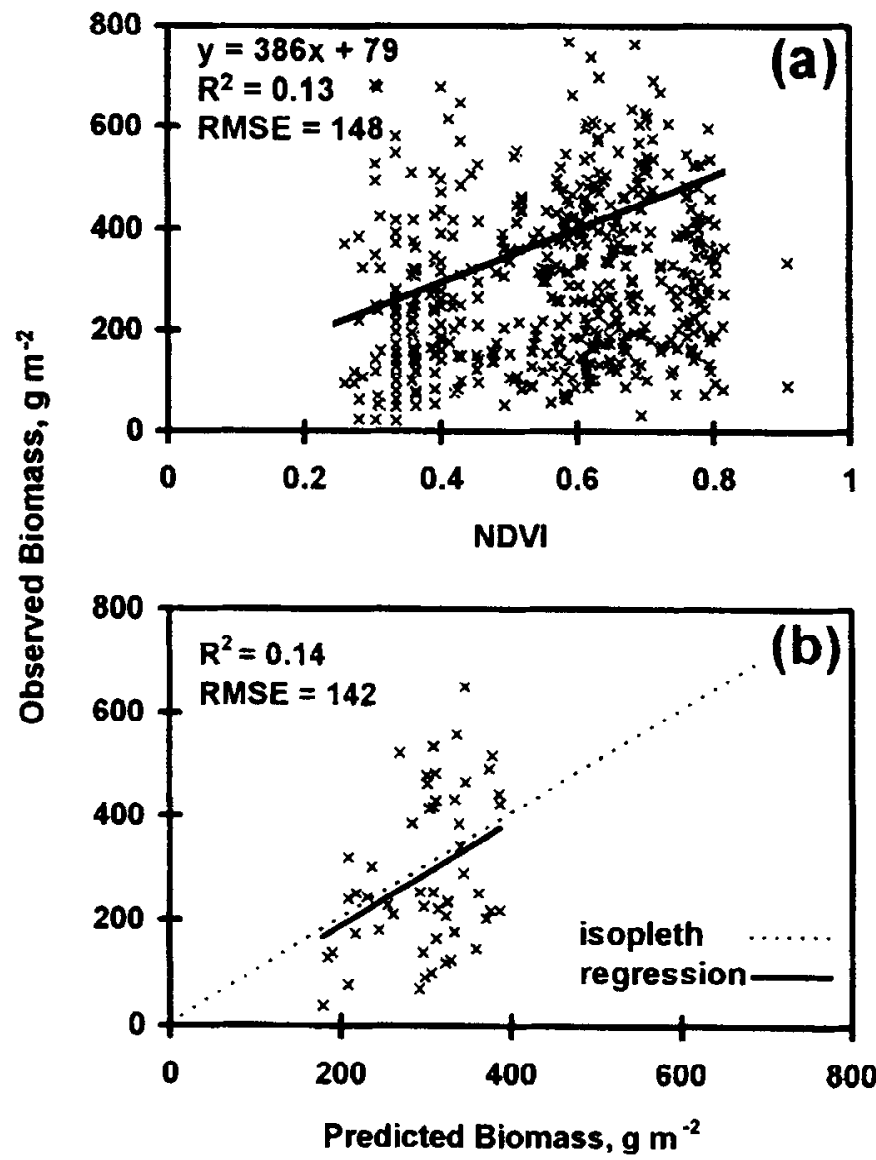

Fig. 1. Prediction of standing forage biomass from NDVI (1991-1995). (a) linear regression of NDVI on biomass, (b) model validation, $R M S E=$ square root of the mean square error.

ial. Crop studies have demonstrated that NDVI may not be related linearly to biomass when it is measured over time. Indeed, the NDVI has been shown to decrease as the proportion of photosynthetically active tissue in a plant decreases (Hinzman et al. 1986, Nageswara-Rao et al. 1992).

Multiple Regression Models. Richardson and Everitt (1992) indicated that temporal and spatial adjustments to the NDVI may be needed to apply it across multiple stages of plant growth. As a result, we included Julian day (JD), range site typc, NDVI, and all reflectance data as possible inputs in the development of multiple regression (MR) models to predict SFB.

The optimal MR model for predicting SFB developed from data encompassing all years of this study was:

$$
\mathrm{SFB}=3.5[\mathrm{JD}]-43.7[460 \mathrm{~nm} \mathrm{RFV}]+1,099[\mathrm{NDVI}]-992
$$

Although this model accounted for a modest amount of the variation in SFB $\left(R^{2}=0.62, S E E=98\right)$, it represented a significant improvement in predictive accuracy compared to the linear regression of observed SFB on NDVI. Chlorophyll absorption bands at $460 \mathrm{~nm}$ have been reported to decrease after vegetation becomes physiologically mature (Hinzman et al. 1986). In this study, reflectance at $460 \mathrm{~nm}$ was negatively correlated $(r=-0.59)$ with biomass and may have served as an indicator of advancing plant maturity.

Performance of the MR model when used to predict standing forage biomass (SFB) from validation data is shown in Fig. 2a. 


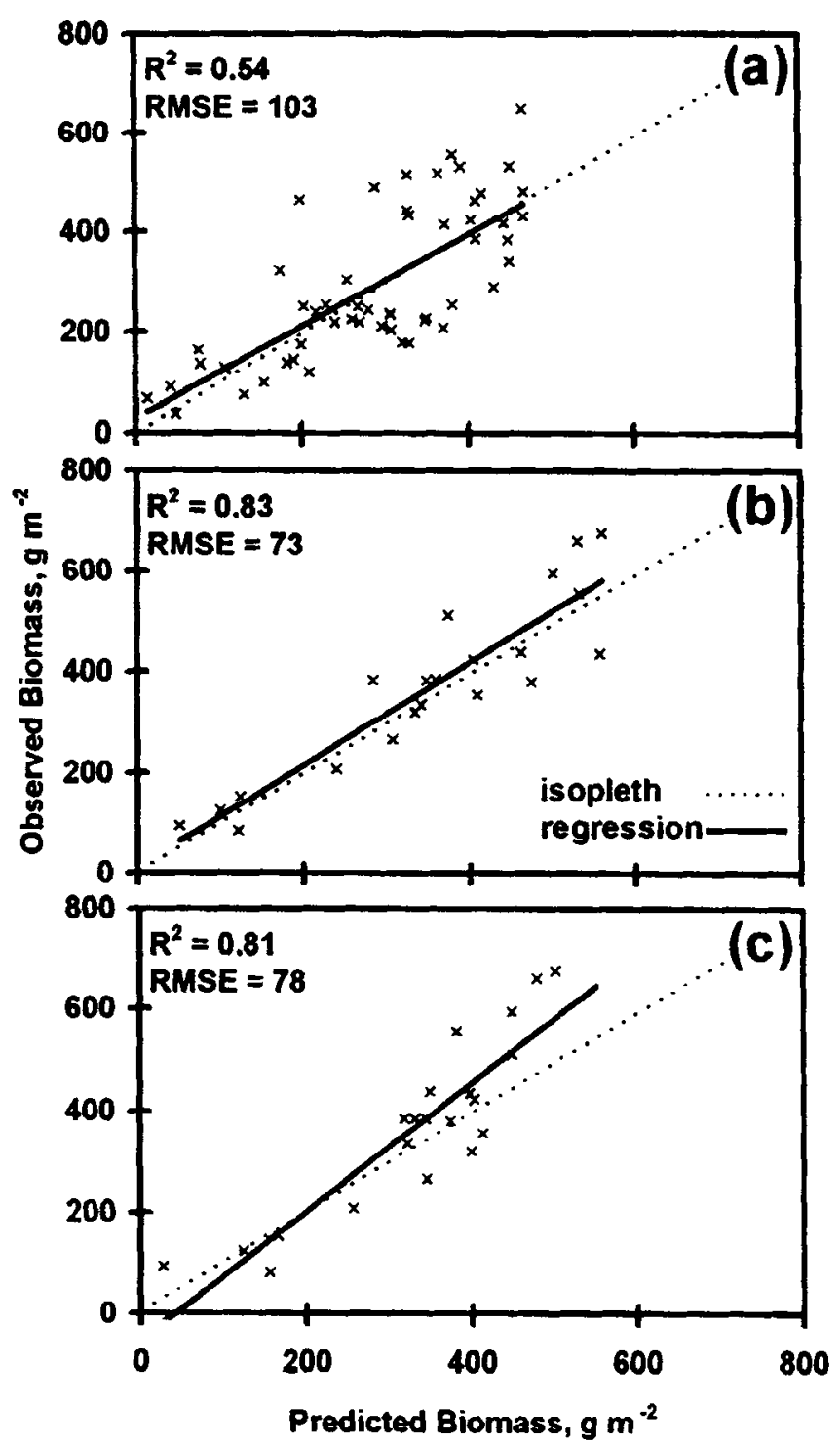

Fig. 2. Prediction of standing forage biomass by MR: validation data. (a) 1992-1995, (b) 1995 - canopy height included, (c) 1995 canopy height excluded, RMSE = square root of the mean square error.

Little prediction bias was apparent by comparison of the relative positions of the regression line and the isopleth. Distribution of the observed values indicated that the model had limited utility for predicting SFB above $500 \mathrm{~g} \mathrm{~m}^{-2}$, even though this was well within the range of SFB values used to construct the model (range $=23$ to $768 \mathrm{~g} \mathrm{~m}^{-2}$; mean $=299 \mathrm{~g} \mathrm{~m}^{-2}$ ).

The tallgrass prairie region of east-central Kansas can yield more than 4,000 $\mathrm{kg} \mathrm{ha}^{-1}$ SFB (Launchbaugh and Owensby 1978). Observations during this study indicated that upland plant community canopies commonly closed 0.4 to $0.6 \mathrm{~m}$ above ground level as early in the growing season as June (data not shown). As a result, shading of basal structures of the plant had potential to cause quantitative underestimates of forage reflectance. A Robel pole measurement was added to each of the plots measured during the 1995 growing season $(n=207$; Table 1$)$. This was done to determine if greater variation in SFB could be accounted for by providing an index of the height at which the vegetation canopy closed.
The optimal MR model developed to predict SFB from data collected during the 1995 growing season was:

$$
\mathrm{SFB}=2.0[\mathrm{JD}]+70.5[\mathrm{CH}]+665[\mathrm{NDVI}]-783
$$

It accounted for approximately $78 \%$ of the variation in SFB during 1995 (SEE = 76). Prediction of SFB from validation data was similarly accurate using this model (Fig. 2b), reflecting only slight bias. When these data were modeled without canopy closure height $(\mathrm{CH})$, the optimal predictive equation had a substantially reduced level of accuracy $(S F B=3.5[J D]+6.0[810 \mathrm{~nm}$ $\left.\mathrm{RFV}]+980[\mathrm{NDVI}]-1,204 ; \mathrm{R}^{2}=0.57 ; \mathrm{SEE}=105\right)$.

The coefficients of determination $\left(R^{2}\right)$ and the RMSE from model validation efforts were similar for multiple regression (MR) models with and without $\mathrm{CH}$ (Figs. $2 \mathrm{~b}$ and $2 \mathrm{c}$ ); however, when $\mathrm{CH}$ was excluded, the model tended to underpredict SFB values above $500 \mathrm{~g} \mathrm{~m}^{-2}$ (Fig. 2c). A similar phenomenon was noted when the MR equation (without $\mathrm{CH}$ ) from all years of the study was used to predict SFB from validation data (Fig. 2a). This information was interpreted to suggest that inclusion of $\mathrm{CH}$ in MR models derived from ground-level radiometry can improve prediction of SFB. In fact, of all variables considered for the 1995 MR model, CH had the strongest correlation to SFB $(r=0.81)$. The Robel pole technique for measuring $\mathrm{CH}$ was easily incorporated with field radiometry procedures in this study and did not require spending a significant amount of extra time at each plot.

Neural Network Models. The NN model of SFB developed from data encompassing all years of the study included the following inputs: Julian date (JD), range site type, incident radiation, NDVI, and all reflectance data. General architecture of the network involved a single hidden layer of 12 nodes. Initial node weights for both the input and hidden layer were in the range of \pm 1.50. The fully trained NN model had an average absolute prediction error of $9.8 \%$ and accounted for $76 \%$ of the variation in SFB across the growing season. Variables of greatest relative importance in predicting SFB were reflectance values at 460,660 , and $760 \mathrm{~nm}$. Of secondary importance were Julian day and reflectance at 560 and $610 \mathrm{~nm}$. Inputs of low importance in SFB prediction were incident radiation and range site type. Previous research indicated that soil differences between range sites can have a profound effect on spectral reflectance (Richardson and Everitt 1992); however, soil color and texture appeared to vary little across range sites in this study. This may explain why range site type was not a crucial factor for predicting SFB.

The neural network (NN) developed with data from all years in this study, when tested using the validation data set, yielded reasonably accurate predictions of $\mathrm{SFB}\left(\mathrm{R}^{2}=0.79\right.$; Fig. $\left.3 \mathrm{a}\right)$. This represented a substantial improvement in predictive accuracy over the corresponding single component or multicomponent linear models (Figs. 1a and 2a, respectively). Zhuang and Engel (1990b) reported that $\mathrm{NN}$ of a structure similar to those used in our study classified multispectral remotely sensed data with greater accuracy than did statistical methods. Similarly, Landsat Thematic Mapper classification by NN resulted in fewer errors in prediction than conventional methods (Benediktsson et al. 1990, Hepner et al. 1990). Moreover, Key et al. (1989) showed that NNs had greater tolerance for error than statistical classification methods for highly complex, remotely sensed images.

One of the advantages to using NN modeling for intricate and highly variable reflectance information is that no assumptions about the distribution of the data are needed. Zhuang and Engel 


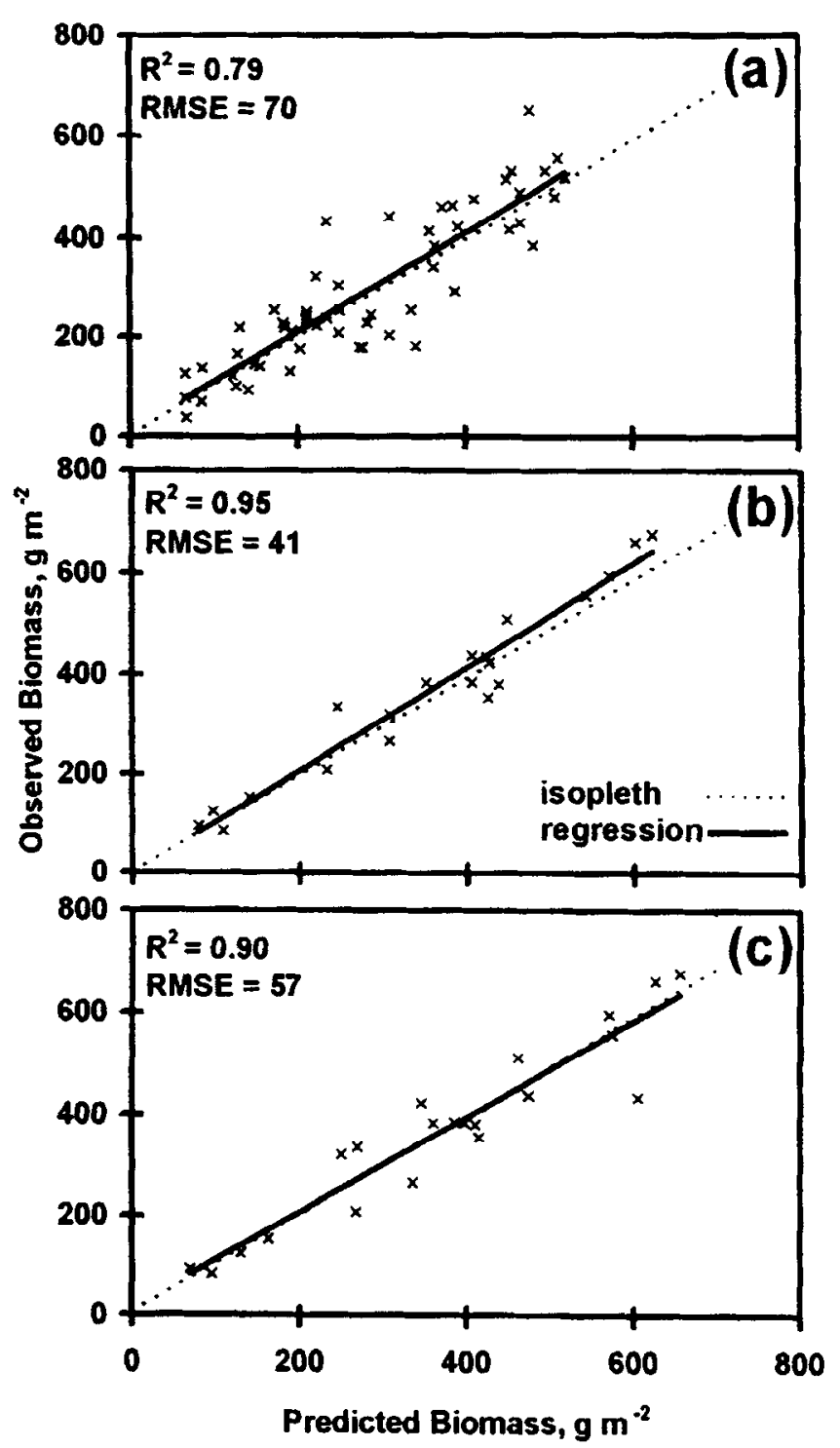

Fig. 3. Prediction of standing forage biomass by NN: validation data. (a) 1992-1995, (b) 1995 - canopy height included, (c) 1995 - canopy height excluded, RMSE = square root of the mean square error.

(1990a, 1990b) remarked that properly structured NNs, by nature, determine the true distribution of data during their training. The key to successful NN modeling, therefore, is collecting training data that are representative of the population under study. In addition, Kohzadi et al. (1995) noted that the decision to apply a particular mathematical function to a set of data characterized by nonlinearity can be quite subjective. Zhuang and Engel (1990a) suggested that an additional advantage of using NNs in developing predictive models is the lack of need to make special adjustments for nonlinearity.

The NN model of standing forage biomass (SFB) developed from data collected during 1995 (NN95+CH) was architecturally similar to the NN model for all years. The sole difference between the 2 was the addition of the canopy height variable in 1995. Standing forage biomass was estimated with an absolute error of $8.3 \%\left(R^{2}=0.86\right)$ during model construction. Those inputs of highest relative importance in the prediction of SFB were canopy closure height $(\mathrm{CH})$, NDVI, and reflectance at 560 ,
660 , and $810 \mathrm{~nm}$. Inputs of lowest relative ranking were range site type, incident radiation, and reflectance at 710 and $760 \mathrm{~nm}$. The performance of $\mathrm{NN} 95+\mathrm{CH}$ in predicting SFB from 1995 validation data is shown in Fig. 3b. Standing forage biomass in 1995 was predicted with a higher degree of accuracy by the NN than by the corresponding MR model (Fig. 2b). This is in agreement with previous researchers who reported that NN modeling of untransformed data was more accurate than traditional regression methods (Elizondo et al. 1994, Brethour 1994, Pierce et al. 1994).

In order to evaluate the influence of $\mathrm{CH}$ on the predictive abilities of the NNs developed in this study, a second NN that excluded $\mathrm{CH}$ as a variable was constructed to predict SFB from 1995 data (NN95-CH). Inputs of greatest relative importance to NN95$\mathrm{CH}$ in predicting SFB were NDVI and reflectance at 460 and 610 $\mathrm{nm}$. Inputs of lowest importance were incident radiation and reflectance at 660 and $710 \mathrm{~nm}$.

Comparison of NN95-CH to NN95+CH revealed few differences in predictive accuracy during model training; both accounted for an equal proportion of variability in SFB $\left(R^{2}=0.86\right)$ and had similar levels of absolute prediction error $(8.2$ vs. $8.3 \%$, respectively). Small differences in accuracy appeared when NN95-CH was used to predict SFB from validation data (Fig. 3c). Inclusion of $\mathrm{CH}$ in the $\mathrm{NN}$ model of $1995 \mathrm{SFB}$ resulted in a $28 \%$ reduction in the RMSE and increased the proportion of variability accounted for in the validation data set by approximately 5 percentage units.

The effect of adding canopy closure height $(\mathrm{CH})$ to multiple regression (MR) and neural network (NN) models of SFB led us to conclude that shading of basal plant structures may be a significant impediment in developing predictive models of SFB. In grassland ecosystems where a substantial amount of biomass accumulates yearly, measurement of $\mathrm{CH}$ may increase the accuracy of reflectance-derived biomass predictions. The relative importance of $\mathrm{CH}$ to predictive accuracy seems to be much greater for MR than NN models when presented with the inputs used in this study. The disadvantage of using a hand-measured index like canopy height in conjunction with multispectral reflectance is that it defeats the purpose of remote sensing.

Prediction of Forb Biomass. Previous research has suggested that reflectance characteristics of planophile and erectophile plant species are different (Jackson and Pinter 1986, Plummer 1988). Planophile plant species (e.g., forbs) tend to reflect red electromagnetic radiation in greater proportions than erectophile plant species (e.g., graminoids). A second objective undertaken during the 1995 growing season was to attempt to develop MR and NN models from reflectance data to predict the percentage of biomass attributable to forbs (PCTF). Inputs to both models included JD, range site type, $\mathrm{CH}$, incident irradiation, NDVI, and all reflectance measurements.

The optimal MR model for prediction of PCTF was:

$$
\mathrm{PCTF}=-0.2[\mathrm{JD}]-3.8[\mathrm{CH}]+65.9
$$

This model accounted for little variability in PCTF $\left(\mathrm{R}^{2}=0.23\right.$, SEE $=14.5$ ). Julian date and $\mathrm{CH}$ were related strongly and negatively to PCTF ( $r=-0.41$ and -0.35 , respectively). We speculate that expressions of both of these inputs in the model stemmed from the same phenomenon; as the growing season advanced, fewer forbs were visible in the vegetation overstory of the study area. This MR model poorly predicted PCTF from validation data (Fig. 4a).

Only weak correlations existed between PCTF and reflectance measurements in the red portion of the spectrum $(610 \mathrm{~nm}, \mathrm{r}=$ 


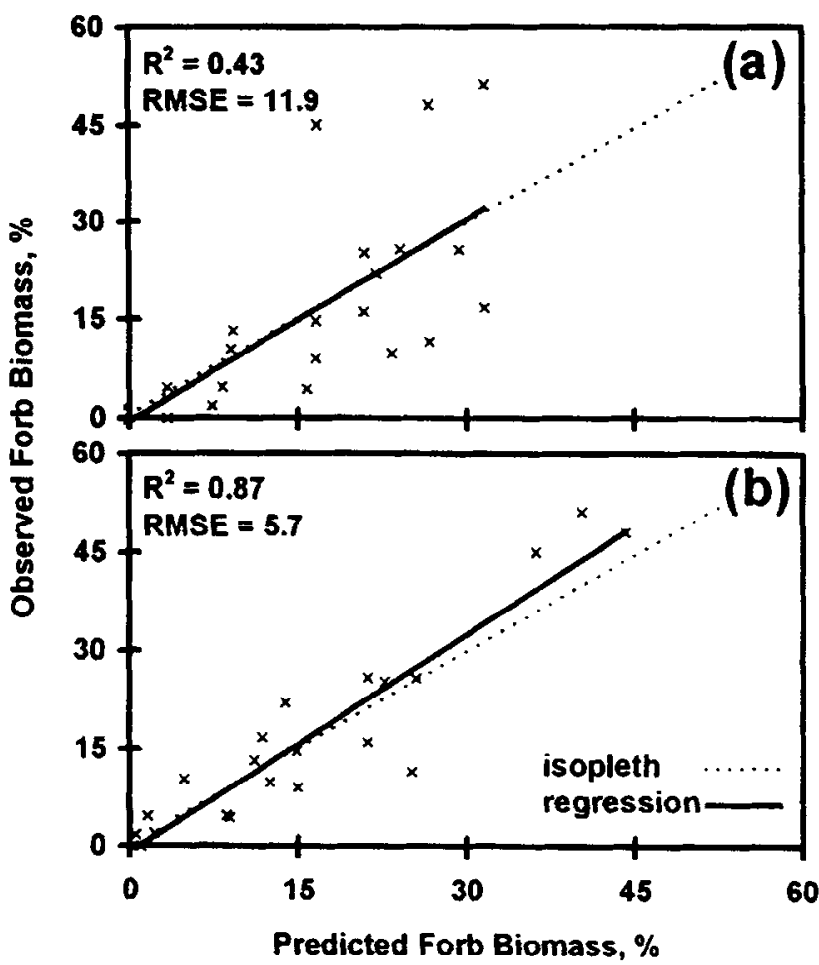

Fig. 4. Prediction of forb standing biomass (1995; \% of total biomass): validation data, (a) $\mathrm{MR}$, (b) $\mathrm{NN}, \mathrm{RMSE}=$ square root of the mean square error.

$0.003 ; 660 \mathrm{~nm}, \mathrm{r}=-0.05 ; 710 \mathrm{~nm}, \mathrm{r}=0.14)$. This seemed to indicate that preferential reflectance of red electromagnetic energy by forbs did not occur in this study. Conversely, PCTF in this study was related more strongly to reflectance in the green portion of the spectrum (460 nm, $\mathrm{r}=0.32 ; 510 \mathrm{~nm}, \mathrm{r}=0.29 ; 560 \mathrm{~nm}, \mathrm{r}=0.29$ ).

The fully trained NN for predicting PCTF had an average absolute prediction error of $13.1 \%\left(\mathrm{R}^{2}=0.59\right)$. The input variables of greatest importance in predicting PCTF were NDVI and reflectance values at $460,560,610$ and $710 \mathrm{~nm}$. Of least importance were JD, $\mathrm{CH}$, and reflectance at $810 \mathrm{~nm}$. Accuracy of the PCTF prediction was increased substantially by using the NN (Fig. 4b) compared to the corresponding MR model. The slight upward bias of the equation line may have been the result of few observations in which forb biomass was greater than $30 \%$ of total biomass.

In contrast to the MR model, the high relative importance of red wavebands (610 and $710 \mathrm{~nm}$ ) in NN prediction of PCTF suggested that the NN and MR models differed substantially in their determination of the most salient input variables. The improved accuracy of prediction for the $\mathrm{NN}$ implies that reflectance in the red region may be important in discriminating botanical composition. Further investigation of the reflectance characteristics of mixed canopy grasslands is warranted to resolve this issue.

Conclusions. Both the neural network (NN) and multiple regression (MR) models used in our study predicted seasonal changes in standing forage biomass (SFB) with an acceptable degree of accuracy; however, NNs described the changes in SFB in validation data with greater accuracy and were able to more accurately predict the percentage of biomass attributable to forbs than MR models. The recent degree of success researchers have experienced using $\mathrm{NN}$ to model a variety of agronomic and ecological data indicates that they will play a key role in the development of process-oriented biospheric models of the future.

\section{Literature Cited}

Aase, J.K., A.B. Frank, and R.J. Lorenz. 1987. Radiometric reflectance measurements of Northern Great Plains rangeland and crested wheatgrass pasture. J. Range Manage. 40:299-302.

Anderson, K.L. and C.L. Fly, 1955. Vegetation-soil relationships in Flint Hills bluestem pastures. J. Range Manage. 8:163-169.

Anderson, G.L. and J.D. Hanson. 1992. Evaluating hand-held radiometer derived vegetation indices for estimating above ground biomass. Geocarto Int. 7:71-78.

Benediktsson, J.A., P.H. Swain, and O.K. Ersoy. 1990. Neural network approaches versus statistical methods in classification of multisource remote sensing data. IEEE Trans. Geosci. Remote Sensing 28(4):540-552.

Biondini, M.E. 1992. Remote sensing uses in agriculture, p. 77-83. In: Proceedings, Advanced Computer Applications in Animal Agriculture. Infomart, Dallas, Tex.

Bochereau, L., P. Bourgine, and B. Palagos. 1992. A method for prediction by combining data analysis and neural networks: application to prediction of apple quality using near infra-red spectra. J. Agr. Eng. Res. 51:207-216.

Brethour, J.R. 1994. Estimating marbling score in live cattle from ultrasound images using pattern recognition and neural network procedures. J. Anim. Sci. 72:1425-1432.

Cropscan. 1994. Multispectral Radiometer User's Manual. Cropscan, Inc. Rochester, Minn.

Elizondo, D.A., R.W. McClendon, and G. Hoogenboom. 1994. Neural network models for predicting flowering and physiological maturity of soybean. Trans. ASAE 37(3):981-988.

Hepner, G.F., T. Logan, N. Ritter, and N. Bryant. 1990. Artificial neural network classification using a minimal training set: comparison to conventional supervised classification. Photogrammetric Eng. Remote Sensing 56(4):496-473.

Hinzman, L.D., M.E. Bauer, and C.S.T. Daughtry. 1986. Effects of nitrogen fertilization on growth and reflectance characteristics of winter wheat. Remote Sensing Environ. 19:47-61.

Jackson, R.D. and P.J. Pinter. 1986. Spectral response of architecturally different wheat canopies. Remote Sensing Environ. 20:43-56.

Jackson, R.D., P.N. Slater, and P.J. Pinter, Jr. 1983. Discrimination of growth and water stress in wheat by various vegetation indices through clear and turbid atmospheres. Remote Sensing Environ. 13:187-208.

Jensen, A., B. Lorenzen, H.S. D stergaard, and E.K. Hvelplund. 1990. Radiometric estimation of biomass and nitrogen content of barley grown at different nitrogen levels. Int. J. Remote Sensing 11:1809-1820.

Jurik, M. 1993. What is a neural network, p. 85-92. In: Braincel ${ }^{(0)}$ Ver. 2.0 User's Manual. Promised Land Technologies, Inc. New Haven, Conn.

Key, J., J.A. Maslanik, and A.J. Schweiger. 1989. Classification of merged AVHRR and SMMR Arctic data with neural networks. Photogrammetric Eng. Remote Sensing 55(9):1331-1338.

Kohzadi, N,. M.S. Boyd, I. Kaastra, B.S. Kermanshahi, and D. Scuse. 1995. Neural networks for forecasting: an introduction. Can. J. Agr. Econ. 43:463-474.

Launchbaugh, J.L. and C.E. Owensby. 1978. Kansas rangelands: their management based on a half century of research. Kansas Agr. Exp. Sta. Bull. 622.

Miller, G.P., M. Fuchs, M.J. Hall, G. Asrar, E.T. Kanemasu, and D.E. Johnson. 1984. Analysis of seasonal multispectral reflectances of smaller grains. Remote Sensing Environ. 14:153-167.

Mitchell, A.R., P.J. Pinter, Jr., J.N. Guerrero, C.B. Hernandez, and V.L. Marble. 1990. Spectral reflectance measurements of alfalfa under sheep grazing. Agron. J. 82:1098-1103. 
Nagaswara-Rao, R.C., J.H. Williams, V.M. Rao, and K.D.R. Wadia. 1992. A hand-held red-infrared radiometer for measuring radiation interception by crop canopies. Field Crops Res. 29:353-360.

Olson, K.C., R.C. Cochran, D.C. Hartnett, C.E. Owensby, and D.E. Johnson. 1995. Effects of grazing system and stocking rate on cowcalf performance in the Flint Hills. pp. 1-3 In: 1995 Cattleman's Day. Kansas Agric. Exp. Sta. Report of Progress No. 727.

Owensby, C.E., R.C. Cochran, and E.F. Smith. 1988. Stocking rate effects on intensive-early stocked Flint Hills bluestem range. J. Range Manage. 41:483-487.

Pearson, R.L., L.D. Miller, and C.J. Tucker. 1976. Hand-held spectral radiometer to estimate gramineous biomass. Appl. Optics 15(2):416-418.

Pierce, L.E., K. Sarabandi, and F.T. Ulaby, 1994. Application of an artificial neural network in canopy scattering inversion. Int. J. Remote Sensing 15:3263-3270.

Plummer, S.E. 1988. Exploring the relationships between leaf nitrogen content, biomass and the near-infrared/red reflectance ratio. Int. J. Remote Sensing 9:177-183.
Richardson, A.J. and J.H. Everitt. 1992. Using spectral vegetation indices to estimate rangeland productivity. Geocarto Int. 7:63-69.

Robel, R.J., J.N. Briggs, A.D. Dayton, and L.C. Hulbert. 1970. Relationships between visual obstruction measurements and weight of grassland vegetation. J. Range Manage. 23:295-297.

SAS Institute Inc. 1985. SAS User's Guide. SAS Institute, Inc. Cary, N.C.

Stanley, J. and E. Bak. 1988. Introduction to Neural Networks. California Scientific Software. Sierra Madre, Calif.

Thai, C.N. and R.L. Shewfelt. 1991. Modeling sensory color quality of tomato and peach: neural networks and statistical regression. Trans. ASAE 34(3):950-955.

Zhuang, X. and B.A. Engel. 1990a. Neural networks for applications in agriculture. ASAE Paper No. 90-7024. St. Joseph, Mich.

Zhuang, X. and B.A. Engel. 1990b. Classification of multispectral remote sensing data using neural networks vs. statistical methods. ASAE Paper No. 90-7552. St. Joscph, Mich. 